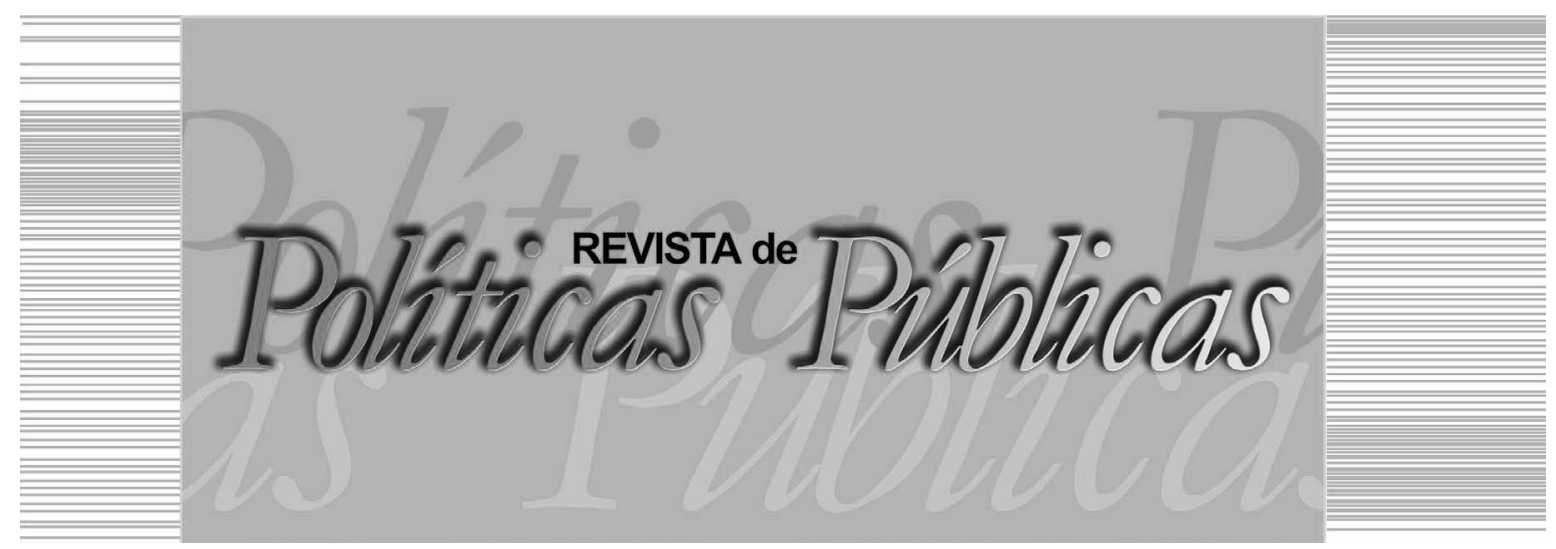

\title{
POLITICAS PÚBLICAS PARA A JUVENTUDE NOS PLANOS PLURIANUAIS DE 2004-2007, 2008-2011 E 2012-2015
}

\author{
André Nunes ${ }^{1}$ \\ Mauro Eduardo Del Grossi ${ }^{2}$ \\ Jovanio Luiz Pereira ${ }^{3}$ \\ Denis Costa Reis ${ }^{4}$
}

\section{Resumo}

O Plano Plurianual, a Lei de Diretrizes Orçamentárias e a Lei Orçamentária Anual são instrumentos constitucionais do poder público para estabelecer onde e como os seus recursos serão utilizados.Nas últimas décadas as políticas públicas para a juventude no Brasil passaram a ter um papel destacado, tanto na legislação, quanto no volume financeiro destinado a executá-las.Este artigo objetiva analisar os Planos Plurianuais de 2004-2007, 2008-2011 e 2012-2015, bem como as estimativas de receita da União nestes períodos, e,com base na

Economista, Doutor em Economia pela Universidade de Brasília (UnB), Professor do Programa de Pós-graduação em Gestão Pública (PPGP) e na Graduação de Gestão do Agronegócio da UnB. E-mail: andrenunes@unb.br

2 Engenheiro Agrônomo, Doutor em Economia pela Universidade Estadual de Campinas (UNICAMP), Pós-doutorado em Medidas de Segurança Alimentar, Professor Associado na Faculdade UnB Planaltina, integrante do Programa de Pós-Graduação em Agronegócios (PROPAGA) e do PPGP. E-mail: delgrossi@unb.br

3 Contador, Mestrando em Gestão Pública pelo PPGP da UnB. E-mail: jovaniop@hotmail. com / Universidade de Brasília - UnB: Campus de Planaltina - Vila Nossa Senhora de Fátima- Brasília, DF. CEP: 70354-050.

4 Filosofo e Administrador, Mestrando em Gestão Pública pelo PPGP/UnB, Servidor Público do Secretaria de Estado da Mulher do Distrito Federal (SEM/DF). E-mail: denis_reis@ hotmail.com / Secretaria de Estado da Mulher - SEM-DF: SCN, Ed. Venâncio 2000 Brasília, DF. CEP: 70000-000 
execução orçamentária anual, identificar quais foram os programas desenvolvidos pelo Governo Federal destinados à emancipação da juventude. Os resultados apontam elevação dos gastos da União com a juventude nos três períodos e menor execução desses gastos no último período analisado.

Palavras-chave: Plano Plurianual, políticas públicas, juventude.

\title{
PUBLIC POLICIES FOR YOUTH IN THE PLURIANNUAL PLANS OF 2004-2007, 2008-2011 AND 2012-2015
}

\begin{abstract}
The Pluriannual Plan, the Budget Guidelines Law and the Annual Budget Law are the public power's constitutional instruments to establish where and how its resources will be used. In the last decades, public policies for the youth in Brazil have come to play a prominent role both in legislation and financial volume destined to implement them. This article aims to analyze the Pluriannual Plans of 2004-2007, 2008-2011 and 2012-2015, as well as the Union's revenue estimates for these periods and based on the annual budgetary execution, identify the programs developed by the Federal Government destined to youth's emancipation. The results show an increase in the Union's spending on youth in the three periods and the lower execution of these expenditures in the last analyzed period.
\end{abstract}

Key words: Pluriannual Plan, public policies, youth.

\section{INTRODUÇÃO}

Na virada do milênio, os países-membros da Organização das Nações Unidas (ONU) proclamaram, durante a Conferência do Milênio, uma agenda para o desenvolvimento global, cujas políticas centrais estão relacionadas aos anseios e bem-estar da população, em especial dos mais necessitados. Quanto às metas do milênio para a juventude, decidiu-se "[...] formular e aplicar estratégias que proporcionem aos jovens de todo o mundo a possibilidade real de encontrar um trabalho digno e produtivo." (ORGANIZAÇÃO DAS NAÇÕES UNIDAS, 2000, p. 9). Por se tratar de problemas globais nos quais o Brasil possui destaque considerável, o sucesso rumo ao desenvolvimento do país depende de parcerias que demonstrem clareza e transparência quanto aos reais interesses das partes envolvidas nesse processo. (SCHMITZ, 2014).

Essas metas resultaram de intensos debates nos anos anteriores, quando as políticas públicas, tanto econômicas, quanto sociais, ganharam maior visibilidade ante a preocupação dos governos com a 
restrição de gastos, gerando assim novas visões sobre os seus papéis, com vistas ao equilíbrio entre receitas e despesas. (SOUZA, 2006). Já as políticas públicas voltadas para a juventude nasceram da clara defesa dos jovens como sujeitos de direitos. (SPOSITO; CARRANO, 2003).

No Brasil ocorre desde os anos 1990 um intenso debate sobre os rumos e os limites da política social. (JACCOUD, 2005). No que tange à adolescência e juventude, a produção teórica vem apresentando discussões e conceitos igualmente complexos, tendo em vista que a própria definição categórica dos temas utiliza critérios históricos e culturais (DAYRELL, 2003), de forma que a percepção social sobre estes tende a ser ambígua e contraditória (PEDROSO; SALLES, 2014). Enquanto o termo adolescência parece estar ligado a categorias psicológicas e a experiências subjetivas, a juventude relaciona-se mais aos campos das teorias sociológicas e históricas (SILVA; LOPES, 2009). Com os benefícios da tecnologia e da sociedade em rede, sabe-se que os jovens de hoje possuem mais conexões do que os jovens de gerações passadas. Porém, nem sempre são definidas as fronteiras que as separam, especialmente da adolescência para a juventude (FEIXA; LECCARDI, 2010).

Para a Organização Mundial de Saúde (OMS, 1985) a adolescência compreende o período entre 10 e 19 anos. No Brasil, em termos legais, o Estatuto da Juventude delimitou seu escopo de atuação ao definir a juventude como pessoas entre 15 e 29 anos de idade ${ }^{1}$, o que pode facilitar o objeto de estudo, uma vez que o identifica simplesmente pela faixa etária. (BRASIL, 2013b). Um fator comum é que em diferentes contextos de desenvolvimento, a convivência familiar e a escola têm sido apresentadas como benefícios positivos e fundamentais para a transição etária (DESSEN; POLONIA, 2007; ZAPPE; DELL'AGLIO, 2016).

Dentre as principais barreiras identificadas, a priori, estão as dificuldades de se estabelecer políticas públicas consistentes, uma vez que estas esbarram nas próprias limitações humanas, especialmente quanto à equidade e eficiência, que muitas vezes superam os campos da própria administração e gestão de políticas públicas (HOOD, 1991), o que implica afirmar que este é um tema que necessita ser visto e revisto continuadamente, até porque políticas públicas são escolhas entre o que o governo faz ou deixa de fazer. (BILHIM, 2008). Embora "[...] desde o começo, a vocação messiânica 
foi apropriada pelo Estado, ou talvez confiada a ele." (BAUMAN, 2013, p. 65), nem sempre este conseguiu cumprir devidamente o seu papel, tendo em vista que teoria e prática são conceitos difíceis de serem alinhados, especialmente em organismos complexos como na administração pública. (DENHARDT, 2012).

Apesar de a juventude ter direitos cada vez mais assegurados, acrescenta-se a tais dificuldades a urgente e expressiva demanda em torno dos diferentes temas no campo das políticas públicas para a juventude, tais como educação (CARVALHO; NOMA, 2011), trabalho urbano (ABRAMO, 2013) e rural (VALADARES; GALIZA, 2014), violência (SILVA; SILVA, 2011), etc.

Acrescenta-se, ainda, o fato de que historicamente os ciclos pelos quais as políticas públicas deveriam atravessar nem sempre são devidamente seguidos (SOUZA, 2006), o que prejudica não só a agenda que reconhece o problema, mas também as propostas de solução ou formulação, que, consequentemente, afetarão as decisões, a implementação e a avaliação de tais políticas. Além do mais, a avaliação, que consiste numa importante etapa ao final desse ciclo, é um campo ainda em construção, mas uma vez realizada possibilita a correção de ações, de forma que se aprecie os programas implementados no que diz respeito aos seus impactos efetivos. (TREVISAN; VAN BELLEN, 2008).

Conceitualmente, conforme Carvalho e Noma (2011, p. 168): "Entende-se por políticas públicas para a juventude o conjunto de princípios, estratégias e ações que estabelece os direitos e responsabilidades dos jovens, afirma suas identidades e potencialidades e cria condições para que esses sujeitos participem da vida social, econômica e cultural do país".

Quanto ao contexto latino-americano, Souza (2006, p. 21) constatou que nos países em desenvolvimento: “[...] ainda não se conseguiu formar coalizões políticas capazes de equacionar minimamente a questão de como desenhar políticas públicas capazes de impulsionar o desenvolvimento econômico e promover a inclusão social de grande parte de sua população".

A ineficácia nas coalizões, por sua vez, resulta na continuidade das demandas. Até mesmo a identificação do tipo de problema que as políticas públicas devem corrigir nem sempre é possível, o que só dificulta ainda mais o processo. (SOUZA, 2006). 


\section{POLÍTICAS PÚBLICAS PARA A JUVENTUDE NOS PLANOS PLURIANUAIS}

DE 2004-2007, 2008-2011, 2012-2015

Por outro lado, apesar das dificuldades, a virada do milênio foi significativa para o Brasil, uma vez que, embora nem sempre homogênea, a estrutura organizacional do sistema de proteção social passou por significativas mudanças, especialmente quanto à descentralização das ações do Estado. Não significa que todas as demandas sociais foram sanadas, mas que a descentralização dessas ações se mostrou dependente direta do tempo de implementação de estratégias dos governos locais. (ARRETCHE, 1999).

Ante o exposto, objetiva-se, com este trabalho, apresentar uma breve síntese constitucional acerca do Plano Plurianual (PPA), das Leis de Diretrizes Orçamentárias (LDO) e da Lei do Orçamento Anual (LOA), juntamente com a apuração das estimativas de receita da União nos anos de 2004 a 2015, seguida pela identificação dos principais programas desenvolvidos para a emancipação da juventude constantes nos Planos de 2004-2007, 2008-2011 e 2012-2015, bem como levantamento de suas execuções nos respectivos orçamentos anuais. Ressalta-se que este trabalho reconhece a existência de outros programas constantes nos Planos que, embora a juventude não seja neles citada como público-alvo, a execução de suas ações permite que de alguma forma ela seja beneficiada direta ou indiretamente por eles, como é o caso do programa Universidade do Século XXI no PPA 2004-2007 e Brasil Universitário, no PPA 2008-2012, voltados para a ampliação do ensino e pesquisa. ${ }^{2}$

\section{O PLANO PLURIANUAL}

O PPA, a LDO e a LOA, dentre outras, são atribuições do Congresso Nacional, conforme Constituição Federal (CF) de 1988. Quanto à fiscalização, compete aos poderes Legislativo, Executivo e Judiciário manter de forma integrada sistema de controle interno com a finalidade de avaliar o cumprimento das metas previstas no PPA, a execução dos programas de governo e dos orçamentos da União, dentre outras. Em resumo, o PPA é um plano de médio prazo que estabelece de forma regionalizada as diretrizes, objetivos e metas da administração pública federal para as despesas de capital e outras delas decorrentes e para as relativas aos programas de duração continuada, ao longo de um período de quatro anos. (BRASIL, 2010a).

A LDO compreende as metas e prioridades da administração pública federal, incluindo as despesas de capital para o exercício fi- 
nanceiro subsequente, orienta a elaboração da LOA, dispõe sobre as alterações na legislação tributária e estabelece a política de aplicação das agências financeiras oficiais de fomento (BRASIL, 2010a). O orçamento público tem sido aprimorado no decurso dos últimos anos, deixando de atuar como no princípio, isto é, como um instrumento de controle, mas sendo também identificado como um instrumento gerencial e de planejamento. (NUNES; OLIVEIRA; BEÚ, 2015).

As estimativas de receitas anuais da União constante na LOA para os exercícios financeiros no período entre 2004-2015 tiveram os seguintes montantes, conforme Tabela 1. (BRASIL, 2004, 2005b, 2006b, 2007b, 2008a, 2008d, 2010b, 2011a, 2012c, 2013a, 2014, 2015).

Tabela 1 - Estimativas de Receitas da União entre 2004-2015:

\begin{tabular}{|c|c|c|c|c|c|c|c|c|}
\hline ANO & Lei $n^{0}$ & $\begin{array}{c}\text { Valores } \\
\text { (milhöes) } \\
\text { RS } \\
\end{array}$ & ANO & Lein $^{0}$ & $\begin{array}{c}\text { Valores } \\
\text { (milhöes) } \\
\text { RS } \\
\end{array}$ & ANO & Lein ${ }^{0}$ & $\begin{array}{c}\text { Valores } \\
\text { (milhöes) RS }\end{array}$ \\
\hline 2004 & $10.873 / 2004$ & 1.502 .129 & 2008 & $11.647 / 2008$ & 1.424 .390 & 2012 & $12.595 / 2012$ & 2.257.289 \\
\hline 2005 & $11.100 / 2005$ & 1.642 .362 & 2009 & $11.897 / 2008$ & 1.660 .729 & 2013 & $12.798 / 2013$ & 2.276 .516 \\
\hline 2006 & $11.306 / 2006$ & 1.702 .917 & 2010 & $12.214 / 2010$ & 1.860 .428 & 2014 & $12.952 / 2014$ & 2.488 .853 \\
\hline 2007 & $11.451 / 2007$ & 1.575 .880 & 2011 & $12.831 / 2011$ & 2.073 .390 & 2015 & $13.115 / 2015$ & 2.982 .546 \\
\hline \multicolumn{2}{|c|}{ Total 2004-2007 } & 6.423 .288 & \multicolumn{2}{|c|}{ Total 2008-2011 } & 7.018 .937 & \multicolumn{2}{|c|}{ Total 2012-2015 } & 10.005 .204 \\
\hline
\end{tabular}

Fonte: Elaborado pelos autores.

O valor total do orçamento nos três períodos analisados foi de 23,4 trilhões de reais, com um suave aumento quanto à expectativa de arrecadação. A parte seguinte deste trabalho consiste em identificar como e quanto deste montante foi planejado e destinado à juventude no Brasil.

\section{PLANEJAMENTO E EXECUÇÃO DE POLÍTICAS PÚBLICAS PARA A JUVENTUDE DE 2004 A 2015}

Uma vez identificados os programas direcionados à juventude em cada PPA, foram extraídos os códigos, os nomes dos programas, o público-alvo e os valores dos gastos previstos. Em seguida, no intuído de verificar qual valor foi executado por programa no orçamento, consultou-se a execução de despesas por programação, disponível na base de dados do Sistema Integrado de Administração 


\section{POLÍTICAS PÚBLICAS PARA A JUVENTUDE NOS PLANOS PLURIANUAIS}

DE 2004-2007, 2008-2011, 2012-2015

Financeira do Governo Federal (SIAFI) - Senado Federal. (BRASIL, 2016).

Para melhor analisar o PPA 2004-2007, realizou-se a distinção entre os gastos previstos no início de 2004 (anexo II do PPA), (BRASIL, 2003), e os valores finais dos gastos revistos em 2006 pelo Ministério do Planejamento (MP) (anexo I do PPA), (BRASIL, 2006a). Assim, foi possível identificar a partir dos valores zerados, por exemplo, quais programas foram inseridos e quais foram abandonados ao longo do período, conforme Tabela 2.

Tabela 2 - Principais Programas para a Juventude no PPA 2004-2007

\begin{tabular}{|c|c|c|c|c|c|c|c|c|c|c|}
\hline \multirow{3}{*}{ CÓD. } & \multirow{3}{*}{ PROGRAMA } & \multirow{3}{*}{$\begin{array}{l}\text { PÚBLICO- } \\
\text { ALVO* }\end{array}$} & \multicolumn{2}{|c|}{ VALORES (MIL R\$) } & \multicolumn{4}{|c|}{ EXECUÇÃO DAS DESPESAS (MIL RS) } & \multirow{2}{*}{\multicolumn{2}{|c|}{ TOTAL EXECUTADO }} \\
\hline & & & PPA-2004 & PPA-2007 & LOA & LOA & LOA & LOA & & \\
\hline & & & Anexo II & Anexol 1 & 2004 & 2005 & 2006 & 2007 & (MLLR\$) & $\%$ \\
\hline 0070 & $\begin{array}{l}\text { Proteção Social } \\
\text { à Infância, } \\
\text { Adolescência e } \\
\text { Juventude }\end{array}$ & $\begin{array}{l}\text { Jovens e } \\
\text { adolescentes } \\
\text { até } 24 \text { anos } \\
\text { em situação de } \\
\text { risco pessoal e } \\
\text { social }\end{array}$ & 995.438 & & 353.523 & 349.370 & & & 702.893 & \\
\hline 0153 & $\begin{array}{l}\text { Promoção e } \\
\text { Defesa dos } \\
\text { Direitos da } \\
\text { Criança e do } \\
\text { Adolescente }\end{array}$ & $\begin{array}{l}\text { Adolescentes de } \\
0 \text { a } 18 \text { anos }\end{array}$ & 68.585 & 116.635 & 24.864 & 18.911 & 13.160 & 22.493 & 79.428 & 68,1 \\
\hline 1008 & Inclusão Digital & $\begin{array}{l}\text { Jovens e outros } \\
\text { seamentos }\end{array}$ & 7.900 & 618.671 & 15.433 & 100.950 & 75.001 & 169.973 & 361.357 & 58,4 \\
\hline 1060 & $\begin{array}{l}\text { Brasil } \\
\text { Alfabetizado / } \\
\text { Educação de } \\
\text { jovens e adultos }\end{array}$ & $\begin{array}{l}\text { Jovens e adultos } \\
\text { analfabetos } \\
\text { com } 15 \text { anos } \\
\text { ou mais }\end{array}$ & 822.696 & 1.927 .514 & 189.407 & 673.239 & 604.821 & 143.040 & 1.610 .507 & 83,6 \\
\hline 1061 & $\begin{array}{l}\text { Brasil } \\
\text { Escolarizado }\end{array}$ & $\begin{array}{l}\text { Adolescentes, } \\
\text { jovens e adultos } \\
\text { da Educação } \\
\text { Básica }\end{array}$ & 14.825 .753 & 9.576 .935 & 3.804 .445 & 1.653 .068 & 2.705 .511 & 3.692 .775 & 11.855 .799 & 123,8 \\
\hline 1062 & $\begin{array}{l}\text { Democratizando } \\
\text { o Acesso à } \\
\text { Educação } \\
\text { Profissional, } \\
\text { Tecnológica e } \\
\text { Universitária }\end{array}$ & $\begin{array}{l}\text { Jovens e adultos } \\
\text { que buscam } \\
\text { melhores } \\
\text { oportunidades } \\
\text { de formaçäo } \\
\text { profissional }\end{array}$ & 9.721 .748 & 5.907 .951 & 1.909 .748 & & & & 1.909 .748 & 32,3 \\
\hline 1066 & $\begin{array}{l}\text { Escola Básica } \\
\text { ideal }\end{array}$ & $\begin{array}{l}\text { Adolescentes, } \\
\text { jovens e adultos } \\
\text { matriculados } \\
\text { nas redes de } \\
\text { ensino }\end{array}$ & 1.547 .717 & & 19.406 & & & & 19.406 & \\
\hline 1116 & Crédito Fundiário & $\begin{array}{l}\text { Familias } \\
\text { sem-terra, } \\
\text { arrendatários, } \\
\text { jovens sem-terra }\end{array}$ & 2.339 .155 & 2.101 .308 & 415.050 & 515.566 & 522.239 & 538.198 & 1.991 .053 & 94,8 \\
\hline 1141 & $\begin{array}{l}\text { Cultura, } \\
\text { Identidade e } \\
\text { Cidadania }\end{array}$ & $\begin{array}{l}\text { Adolescentes } \\
\text { e jovens em } \\
\text { situação de } \\
\text { vulnerabilidade }\end{array}$ & 64.134 & 189.740 & 4.073 & & & & 4.073 & 2,1 \\
\hline
\end{tabular}


André Nunes | Mauro Eduardo Del Grossi $\mid$ Jovanio Luiz Pereira | Denis Costa Reis

\begin{tabular}{|c|c|c|c|c|c|c|c|c|c|c|}
\hline 1245 & $\begin{array}{l}\text { Inserção Social } \\
\text { pela Produção } \\
\text { de Material } \\
\text { Esportivo }\end{array}$ & $\begin{array}{l}\text { Adolescentes } \\
\text { e jovens em } \\
\text { conflito com } \\
\text { a lei }\end{array}$ & 58.186 & 71.793 & 12.680 & 12.402 & 19.167 & 20.372 & 64.621 & 90,0 \\
\hline 1329 & $\begin{array}{l}\text { Primeiro } \\
\text { Emprego }\end{array}$ & $\begin{array}{l}\text { Jovens de } 16 \\
\text { a } 24 \text { anos, } \\
\text { desempregados }\end{array}$ & 1.130 .691 & 549.655 & 51.828 & 100.990 & 93.244 & 100.691 & 346.753 & 63,1 \\
\hline 1350 & $\begin{array}{l}\text { Educação } \\
\text { do Campo } \\
\text { (PRONERA) }\end{array}$ & $\begin{array}{l}\text { Jovens e adultos } \\
\text { assentados da } \\
\text { Reforma Agrária } \\
\text { e da Agricultura } \\
\text { Familiar }\end{array}$ & & 133.668 & & 34.668 & 35.401 & 39.199 & 109.268 & 81,7 \\
\hline 1378 & $\begin{array}{l}\text { Desenvolvimento } \\
\text { do Ensino } \\
\text { Médio }\end{array}$ & $\begin{array}{l}\text { Adolescentes e } \\
\text { jovens e adultos } \\
\text { do ensino } \\
\text { médio }\end{array}$ & & 536.270 & & 279.603 & 75.753 & 141.643 & 496.999 & 92,7 \\
\hline 1385 & $\begin{array}{l}\text { Proteção Social } \\
\text { Especial }\end{array}$ & $\begin{array}{l}\text { Adolescentes, } \\
\text { jovens }\end{array}$ & & 589.584 & & 0 & 127.762 & 163.115 & 290.877 & 49,3 \\
\hline 8028 & Segundo Tempo & $\begin{array}{l}\text { Estudantes } \\
\text { do Ensino } \\
\text { Fundamental e } \\
\text { Médio }\end{array}$ & 138.584 & 462.940 & 48.796 & 123.974 & 130.789 & 123.332 & 426.891 & 92,2 \\
\hline 8034 & ProJovem & $\begin{array}{l}\text { Jovens que } \\
\text { possuam entre } \\
15 \text { e } 29 \text { anos }\end{array}$ & & 862.757 & & 261.687 & 246.549 & 148.179 & 656.415 & 76,1 \\
\hline \multicolumn{3}{|c|}{ TOTAL (RS) } & 31.720 .587 & 23.645 .421 & 6.849 .253 & 4.124.428 & 4.649.397 & 5.303 .010 & 20.926 .088 & 88,5 \\
\hline
\end{tabular}

Fonte: BRASIL. Ministério do Planejamento, Orçamento e Gestão. Secretaria de Planejamento e Investimentos Estratégicos. Plano Plurianual 2004-2007: projeto de lei. Brasília, DF, 2003; BRASIL. Ministério do Planejamento, Orçamento e Gestão. Secretaria de Planejamento e Investimentos Estratégicos. Plano Plurianual 2004-2007: projeto de lei de revisão. Brasília, DF, 2006a; LOA 20042007: BRASIL. Senado Federal. Sistema Integrado de Administração Financeira. Séries Históricas. Execução orçamentária por programação. Base de Dados SIAFI. Brasília, DF, 2016. Disponível em:<https://www12.senado.leg.br/orcamento/loa>. Acesso em: 25 dez. 2016.

Nota: ${ }^{*}$ Com supressões redacionais.

Constatou-se a inserção de quatro novos programas e a descontinuidade de quatro existentes. O valor total executado foi de 20,9 bilhões de reais, o que corresponde a $88,5 \%$ do valor orçado e cerca de $0,33 \%$ da estimativa de receita para o período. Destaca-se o alto percentual executado com os programas Brasil Escolarizado; Crédito Fundiário; Inserção Social pela Produção de Material Esportivo; Desenvolvimento do Ensino Médio e Segundo Tempo, que, juntos, concentram $70 \%$ dos recursos gastos, focados tanto na educação básica, quanto profissional, nos meios de produção, esportes e mercado de trabalho. O Programa Nacional de Inclusão de Jovens (ProJovem) executou $76,1 \%$ do valor previsto no PPA.

Quanto ao Plano Plurianual instituído para o quadriênio 2008-2011, o projeto de lei enviado pelo Presidente Lula ao Congresso Nacional apresentou-se como uma resposta aos desafios de aceleração do crescimento econômico, promoção da inclusão social e redução das desigualdades regionais. (BRASIL, 2007a). 


\section{POLÍTICAS PÚBLICAS PARA A JUVENTUDE NOS PLANOS PLURIANUAIS DE 2004-2007, 2008-2011, 2012-2015}

Dentre as estratégias do MP para o desenvolvimento do País foram incluídas, na agenda social, ações para a juventude que tomaram como base a Pesquisa Nacional por Amostras de Domicílios (PNAD) de 2005, por meio da qual constatou-se que o Brasil possui 50,5 milhões de jovens na faixa etária entre 15 e 29 anos, sendo desenvolvidas ações integradas no âmbito da Política Nacional de Juventude (PNJ) para essa faixa etária com foco na elevação da escolaridade, qualificação social e profissional e desenvolvimento humano. (BRASIL, 2007a).

A Tabela 3 destaca os programas de Governo constantes no anexo I do projeto de lei do PPA 2008-2011 (BRASIL, 2008b), com ações dos programas voltados para a juventude, em paralelo com a execução orçamentária anual.

Assim como a análise realizada quanto ao período 20042007, foram distinguidos os valores orçados no início de 2008 e em 2011, no intuito de identificar quais programas sofreram alterações orçamentárias ao longo do período.

Comparando os dois períodos, identificou-se a exclusão de cinco programas, a retomada de dois programas paralisados, bem como o surgimento de três novos programas voltados para o trabalho, educação e segurança (Ciência, Tecnologia e Inovação para a Inclusão e Desenvolvimento Social; Programa Nacional de Segurança Pública com Cidadania - PRONASCI e Educação por Alternância para a Agricultura Familiar).

Tabela 3 - Principais Programas para a Juventude no PPA 2008-2011

\begin{tabular}{|c|c|c|c|c|c|c|c|c|c|c|}
\hline \multirow{3}{*}{ CÓD } & \multirow{3}{*}{ PROGRAMA } & \multirow{3}{*}{$\begin{array}{l}\text { PÚBLICO- } \\
\text { ALVO* }\end{array}$} & \multicolumn{2}{|c|}{ VALORES (MLR\$) } & \multicolumn{4}{|c|}{ EXECUÇÃO DAS DESPESAS (MIL RS) } & \multirow{2}{*}{\multicolumn{2}{|c|}{ TOTAL EXECUTADO }} \\
\hline & & & PPA-2008 & PPA-2011 & LOA & LOA & LOA & LOA & & \\
\hline & & & Anexol & Bco Dados & 2008 & 2009 & 2010 & 2011 & (MLRS) & $\%$ \\
\hline 0471 & $\begin{array}{l}\text { Ciênncia, Tecnologia } \\
\text { e lnovaçäo } \\
\text { para Inclusãa e } \\
\text { Desenvolvimento } \\
\text { Social } \\
\end{array}$ & $\begin{array}{l}\text { Participantes } \\
\text { do programa da } \\
\text { juventude }\end{array}$ & 451.593 & 486.389 & 238.349 & 134.854 & 198.086 & 53.234 & 624.523 & 128,4 \\
\hline 1008 & Inclusão Digital & $\begin{array}{l}\text { Comunidades e } \\
\text { segmentos }\end{array}$ & 725.693 & 1.582 .248 & 163.290 & 144.051 & 302.025 & 123.489 & 732.855 & 46,3 \\
\hline 1060 & $\begin{array}{l}\text { Brasil Affabetizadoe e } \\
\text { Educacăa de jovens } \\
\text { e adultos }\end{array}$ & $\begin{array}{l}\text { Jovens e } \\
\text { adultos de } 15 \\
\text { anos ou mais } \\
\text { de idade não } \\
\text { alfabetizados }\end{array}$ & 3.040 .728 & 2.988 .713 & 290.456 & 290.519 & 628.252 & 789.219 & 1.998 .446 & 66,9 \\
\hline 1061 & Brasil Escolarizado & $\begin{array}{l}\text { Adolescentes e } \\
\text { jovens }\end{array}$ & 49.835.489 & 49.520 .088 & 7.465 .418 & 10.309.537 & 15.245.512 & 17.981.149 & 51.001 .616 & 103,0 \\
\hline
\end{tabular}


André Nunes | Mauro Eduardo Del Grossi | Jovanio Luiz Pereira | Denis Costa Reis

\begin{tabular}{|c|c|c|c|c|c|c|c|c|c|c|}
\hline 1062 & $\begin{array}{l}\text { Desenvolvimento } \\
\text { da Educação } \\
\text { Profissionale } \\
\text { Tecnológica }\end{array}$ & $\begin{array}{l}\text { Jovense } \\
\text { adultos que } \\
\text { buscam } \\
\text { formação } \\
\text { profissional e } \\
\text { professores }\end{array}$ & 9.389 .308 & 9.522 .102 & 2.027.173 & 2.812.727 & 4.018.189 & 5.897 .529 & 14.755.618 & 155,0 \\
\hline 1116 & Crédito Fundä́rio & $\begin{array}{l}\text { Jovens } \\
\text { sem-terra }\end{array}$ & 2.664 .931 & 2.551 .590 & 396.458 & 514.702 & 367.469 & 378.330 & 1.656.959 & 64,9 \\
\hline 1141 & $\begin{array}{l}\text { Cultura Viva - Arte, } \\
\text { Educaçăo e } \\
\text { Cidadania }\end{array}$ & $\begin{array}{l}\text { Adolescentes e } \\
\text { jovens }\end{array}$ & 672.197 & 619.658 & 119.713 & 119.547 & 107.876 & 78.533 & 425.669 & 68,7 \\
\hline 1245 & $\begin{array}{l}\text { Inclusão Social pelo } \\
\text { Esporte }\end{array}$ & $\begin{array}{l}\text { Adolescentes } \\
\text { e jovens em } \\
\text { confito com } \\
\text { a lei }\end{array}$ & 95.292 & 91.243 & 11.696 & 13.173 & 17.631 & 9.709 & 52.209 & 57,2 \\
\hline 1350 & $\begin{array}{l}\text { Educaăăo do Campo } \\
\text { (PRONERA) }\end{array}$ & $\begin{array}{l}\text { Jovens e } \\
\text { adultos } \\
\text { assentados da } \\
\text { Reforma Agrária } \\
\text { e da Agricultura } \\
\text { Familiar }\end{array}$ & 431.605 & 391.045 & 31.665 & 23.093 & 15.414 & 21.453 & 91.625 & 23,4 \\
\hline 1385 & $\begin{array}{l}\text { Proteção Social } \\
\text { Especial }\end{array}$ & $\begin{array}{l}\text { Adolescentes e } \\
\text { jovens }\end{array}$ & & 996.659 & 188.312 & 172.510 & 255.137 & 263.922 & 879.881 & 88,3 \\
\hline 1453 & $\begin{array}{l}\text { Nacional de } \\
\text { Segurança Pública } \\
\text { com Cidadania - } \\
\text { PRONASCI }\end{array}$ & $\begin{array}{l}\text { Adolescentes e } \\
\text { jovens vitimas } \\
\text { da violência }\end{array}$ & 6.021 .106 & 8.875 .666 & 1.026.111 & 1.237 .820 & 1.425 .745 & 783.900 & 4.473 .576 & 50,4 \\
\hline 6005 & $\begin{array}{l}\text { Educaçăo por } \\
\text { Alternância para } \\
\text { Agricultura Familiar }\end{array}$ & $\begin{array}{l}\text { Jovense } \\
\text { adultos que } \\
\text { vivem no } \\
\text { meio oural e } \\
\text { que buscam } \\
\text { educaçäo } \\
\text { profissional }\end{array}$ & 76.000 & & & & & & & \\
\hline 8028 & Segundo Tempo & $\begin{array}{l}\text { Adolescentes } \\
\text { e jovens que } \\
\text { participam ou } \\
\text { não do sistema } \\
\text { de ensino } \\
\text { regular }\end{array}$ & 725.789 & 728.730 & 191.793 & 210.408 & 175.350 & 215.184 & 792.735 & 108,8 \\
\hline 8034 & Proodvem & $\begin{array}{l}\text { Jovens que } \\
\text { possuam entre } \\
15 \text { e } 29 \text { anos }\end{array}$ & 7.698 .490 & 7.449 .921 & 770.730 & 1.197.434 & 1.377 .331 & 868.068 & 4.213 .563 & 56,6 \\
\hline \multicolumn{3}{|c|}{ TOTAL (RS) } & 81.828.221 & 85.882.098 & 12.921.164 & 17.180 .375 & 24.134.017 & 27.463 .719 & 81.699.275 & 95,1 \\
\hline
\end{tabular}

Fonte: BRASIL. Ministério do Planejamento, Orçamento e Gestão. Secretaria de Planejamento e Investimentos Estratégicos. Plano Plurianual 2008-2011: projeto de lei. Brasília, DF, 2007a; BRASIL. Presidência da República. Lei no 11.653, de 7 de abril de 2008. Dispõe sobre o Plano Plurianual para o período 2008/2011. Diário Oficial da União, Brasília, DF, 8 abr. 2008b. Seção 1; LOA 2008-2011 (BRASIL, 2016).

Nota: * Com supressões redacionais.

O crescimento econômico do Brasil permitiu expressiva elevação dos gastos com a juventude. Os gastos executados com o programa Brasil Escolarizado saltaram de 11,8 bilhões para 51 bi- 
lhões de reais. O valor total de gastos executados passou de 20,9 bilhões entre 2004-2007 para 81,6 bilhões de reais entre 2008-2011, o que correspondeu a cerca de $1,16 \%$ da estimativa de arrecadação da União.

Enquanto alguns programas executaram despesas acima do orçado, outros tiveram gastos menores, como ocorreu com o Educação do Campo. O ProJovem executou 56,6\% do orçamento. Considerando todos os programas, o total executado corresponde a $95,2 \%$ dos programas no PPA.

Quanto ao PPA 2012-2015, sua estrutura reflete as políticas públicas e organiza a atuação governamental em duas frentes: programas temáticos e programas de gestão, manutenção e serviços ao Estado, sendo que os programas destinados exclusivamente a operações especiais não integram o PPA. (BRASIL, 2012b).

Ressalta-se que em relação aos critérios de pesquisa utilizados anteriormente, a estrutura organizacional do PPA foi alterada e deixou de constar o campo ou coluna público-alvo. Dessa forma, os termos utilizados na busca (jovem, jovens, juventude), embora tenham permanecido os mesmos, foram identificados nos campos Objetivos ou Metas, descritos em cada programa, conforme Tabela 4.

A identificação dos programas constantes na Tabela 4, nos quais a juventude é referenciada como parte dos objetivos ou metas foi extraída do anexo I do PPA no qual constam os programas temáticos do Governo. Foram consultados, também, nas leis orçamentárias entre 2012 e 2015 os programas constantes no PPA anterior (Tabela 3) com o objetivo de averiguar se foram ou não continuados pelo governo de Dilma Rousseff, eleita presidente em 2010.

Constatou-se que todos os programas dos Planos anteriores foram descontinuados, sendo criadas novas nomenclaturas e códigos para o período 2012-2015. Em média, os valores previstos no PPA para o ano de 2012 sofreram poucas variações em relação ao final do período, em 2015.

A maioria dos percentuais dos novos programas executados no orçamento ficou abaixo da média observada nos planos anteriores, conforme alguns destaques: Agricultura Familiar, 9\%; Agropecuária Sustentável, abastecimento e comercialização, 10\%; Política para as Mulheres, 7\%; Enfrentamento ao Racismo e Promoção da Igualdade Racial, 18\%; Esporte e Grandes Eventos Esportivos, 
19\%; Autonomia e Emancipação da Juventude, 4\%; Coordenação de Políticas de Prevenção às Drogas e usuários de Crack, 20\%; Reforma Agrária, 19\%.

Tabela 4 - Principais Programas para a Juventude no PPA 2012-2015

\begin{tabular}{|c|c|c|c|c|c|c|c|c|c|c|}
\hline \multirow{3}{*}{ CÓD. } & \multirow{3}{*}{ PROGRA_MA } & \multirow{3}{*}{$\begin{array}{l}\text { OBJETVOSOU } \\
\text { METAS* }\end{array}$} & \multicolumn{2}{|c|}{ VALORES (MLL\$) } & \multicolumn{4}{|c|}{ EXECUÇĀO DAS DESPESAS (MIL RS) } & \multirow{2}{*}{\multicolumn{2}{|c|}{ TOTAL EXECUTADO }} \\
\hline & & & \multirow{2}{*}{$\frac{\text { PPA-2012 }}{\text { Anexol }}$} & \multirow{2}{*}{$\begin{array}{l}\text { PPA-2015 } \\
\text { Bco Dados }\end{array}$} & \multirow{2}{*}{$\frac{L O A}{2012}$} & \multirow{2}{*}{$\frac{L O A}{2013}$} & \multirow{2}{*}{$\frac{L O A}{2014}$} & \multirow{2}{*}{$\begin{array}{l}\text { LOA } \\
2015\end{array}$} & & \\
\hline & & & & & & & & & (MLRS) & $\%$ \\
\hline 1061 & $\begin{array}{c}\text { Brasil } \\
\text { Escolarizado }\end{array}$ & & & & 37.530 & & & & 37.530 & \\
\hline 1062 & $\begin{array}{l}\text { Democratizando } \\
\text { oAcessoà } \\
\text { Educacaão... }\end{array}$ & & & & 927 & & & & 927 & \\
\hline 2012 & $\begin{array}{l}\text { Agriculura } \\
\text { Familiar }\end{array}$ & $\begin{array}{c}\text { Adequar as } \\
\text { condiçöes de crédito } \\
\text { às particularidades } \\
\text { da agricultura } \\
\text { famililar }\end{array}$ & 93.721 .290 & 93.934 .422 & 1.647 .952 & 1.262 .598 & 1.209 .970 & 4.5855 .729 & 8.706 .249 & 9,3 \\
\hline 2014 & $\begin{array}{c}\text { Agropecuána } \\
\text { Sustentável, } \\
\text { Abastecimento } \\
\text { e... }\end{array}$ & $\begin{array}{c}\text { Implantar } 40 \text { projetos } \\
\text { de desenvolvimento } \\
\text { em associaçöes } \\
\text { rurais } \\
\end{array}$ & 216.620.560 & 216.622 .560 & 4.426 .146 & 5.115 .363 & 4.757 .839 & 8.495 .104 & 22.794.452 & 10,5 \\
\hline 2016 & $\begin{array}{c}\text { Politicas para as } \\
\text { Mulheres }\end{array}$ & $\begin{array}{c}\text { Formar } 5.000 \\
\text { jovens muhheres } \\
\text { sobre direitos das } \\
\text { mulheres }\end{array}$ & 266.100 & 298.620 & 22.811 & & & & 22.811 & 7,6 \\
\hline 2030 & $\begin{array}{l}\text { Educaç̄oo } \\
\text { Básica }\end{array}$ & $\begin{array}{l}\text { Elevar a taxa de } \\
\text { frequência à escola } \\
\text { para populaçăo de } \\
15 \text { a } 17 \text { anos }\end{array}$ & 125.836.765 & 127.538.883 & 21.473.702 & 21.240 .264 & 21.353.130 & 20.566 .394 & 84.633 .490 & 66,4 \\
\hline 2031 & $\begin{array}{l}\text { Educação } \\
\text { Profissionale } \\
\text { Tecnológica }\end{array}$ & $\begin{array}{c}\text { Oferecer } 8 \text { milhöes } \\
\text { de vagas para } \\
\text { a educaçăo } \\
\text { profissional }\end{array}$ & 23.387.133 & 23.903.513 & 2.629 .970 & 4.155 .326 & 5.497 .259 & 4.391.957 & 16.674 .512 & 69,8 \\
\hline 2034 & $\begin{array}{c}\text { Enfrentamento } \\
\text { ao Racismo } \\
\text { e Promogäa } \\
\text { da lgualdade } \\
\text { Racial } \\
\end{array}$ & $\begin{array}{l}\text { Instituir medidas } \\
\text { de prevençäo e } \\
\text { enfrentamento do } \\
\text { racismo }\end{array}$ & 312.623 & 337.113 & 12.814 & 16.939 & 24.193 & 9.357 & 63.303 & 18,8 \\
\hline 2035 & $\begin{array}{l}\text { Espotte e } \\
\text { Grandes } \\
\text { Eventos } \\
\text { Espotivos }\end{array}$ & $\begin{array}{c}\text { Ampliar em 50\% } \\
\text { ao ano o acesso } \\
\text { ao esporte a } \\
\text { adolescentes e } \\
\text { iovens }\end{array}$ & 8.011 .322 & 8.968 .372 & 170.449 & 303.666 & 735.126 & 548.333 & 1.757 .574 & 19,6 \\
\hline 2044 & $\begin{array}{l}\text { Autonomiae } \\
\text { Emancipacăäo da } \\
\text { Juventude }\end{array}$ & $\begin{array}{l}\text { Coordenarar as } \\
\text { politicas pubblicas de } \\
\text { juventude }\end{array}$ & 1.781 .806 & 1.8000 .076 & 51.675 & 15.317 & 9.543 & 10.573 & 87.108 & 4,8 \\
\hline 2058 & $\begin{array}{c}\text { Politica Nacional } \\
\text { de Defesa }\end{array}$ & $\begin{array}{l}\text { Profissionalizaçäo } \\
\text { de } 100.000 \text { jovens }\end{array}$ & 52.823 .391 & 54.178 .212 & 7.940 .086 & 7.711 .405 & 9.407 .137 & 7.783 .159 & 32.841.787 & 60,6 \\
\hline 2060 & $\begin{array}{l}\text { Coordenaçãa } \\
\text { de Politicas de } \\
\text { Prevençä́o... } \\
\text { Usuários de } \\
\text { Crack }\end{array}$ & $\begin{array}{l}\text { Capacitar } \\
\text { profissionais de } \\
\text { saúdeque trabalham } \\
\text { com jovens }\end{array}$ & 77.673 & 236.368 & 7.440 & 9.751 & 15.231 & 16.130 & 48.552 & 20,5 \\
\hline
\end{tabular}


POLÍTICAS PÚBLICAS PARA A JUVENTUDE NOS PLANOS PLURIANUAIS DE 2004-2007, 2008-2011, 2012-2015

\begin{tabular}{|c|c|c|c|c|c|c|c|c|c|c|}
\hline 2062 & $\begin{array}{l}\text { Promoçäo } \\
\text { dos Diretios } \\
\text { de Criancas e } \\
\text { Adolescentes }\end{array}$ & $\begin{array}{l}\text { Promover os direitos } \\
\text { de crianças e } \\
\text { adolescentes }\end{array}$ & 1.663.781 & 1.734.756 & 290.993 & 205.859 & 22.303 & 11.498 & 530.653 & 30,6 \\
\hline 2063 & $\begin{array}{l}\text { Promocoäao } \\
\text { dos Direitos de } \\
\text { Pessoas com } \\
\text { Deficiência }\end{array}$ & $\begin{array}{l}\text { Acompanhar } \\
\text { iniciativas que } \\
\text { assegurem que } \\
\text { pessoas com } \\
\text { deficiência estejam } \\
\text { na escola }\end{array}$ & 59.681 & 79.011 & 2.653 & 4.091 & 2.401 & 4.740 & 13.885 & 17,6 \\
\hline 2066 & $\begin{array}{l}\text { Reforma } \\
\text { Agráría... }\end{array}$ & $\begin{array}{l}\text { Atender } 8.000 \text { jovens } \\
\quad \text { e adultos }\end{array}$ & 10.992.911 & 11.096 .331 & 672.661 & 444.453 & 700.961 & 313.240 & 2.137.315 & 19,3 \\
\hline 2071 & $\begin{array}{l}\text { Trabalho, } \\
\text { Empregoe } \\
\text { Renda }\end{array}$ & $\begin{array}{l}\text { Ampliar a oferta } \\
\text { de cursos de } \\
\text { qualificaçäo social e } \\
\text { profissional }\end{array}$ & 248.018 .586 & 248.056.376 & 39.959.581 & 45.952.2936 & 51.085 .017 & 46.592.911 & 183.590.445 & 74,0 \\
\hline \multicolumn{3}{|c|}{ TOTAL (RS) } & 783.573 .622 & 788.782 .613 & 102.135 .801 & 86.437.968 & 94.826 .110 & 93.329 .125 & 376.729 .004 & 47,8 \\
\hline
\end{tabular}

Fonte: BRASIL. Presidência da República. Lei no 12.593, de 18 de janeiro de 2012. Institui o Plano Plurianual da União para o período de 2012 a 2015. Diário Oficial da União, Brasília, DF, seção 1, 19 jan. 2012b; BRASIL. Presidência da República. Lei no 12.595, de 19 de janeiro de 2012. Estima a receita e fixa a despesa da União para o exercício financeiro de 2012. Diário Oficial da União, Brasília, DF, 20 jan. 2012c. Seção 1; LOA 2012-2015 (BRASIL, 2016).

Nota: ${ }^{*}$ Com supressões redacionais.

A estimativa de receitas para o período foi de 10 trilhões de reais. $\mathrm{O}$ valor total do orçamento dos programas ligados à juventude subiu para 788 bilhões de reais, o que representa $7,9 \%$ da estimativa de arrecadação. Contudo, o valor executado foi de 376 bilhões de reais, correspondente a $47 \%$ do valor do orçamento e 3,7\% da estimativa de receitas. Os programas cuja execução foi superior a $50 \%$ do orçado foram Educação Básica, 66\%; Educação Profissional e Tecnológica, 69\%; Política Nacional de Defesa, 60\%; e o programa Trabalho, Emprego e Renda, 74\%.

Dentre os programas identificados nos três planos plurianuais, observou-se que o ProJovem foi instituído pela Lei 11.129, de 30 de junho de 2005 com o objetivo de promover a reintegração do jovem ao processo educacional, sua qualificação profissional e seu desenvolvimento humano (BRASIL, 2005c), sendo assumido pelo Governo Federal como um programa finalístico, integrando as metas governamentais prioritárias e visava beneficiar 6 milhões de jovens e adolescentes urbanos e rurais até o ano de 2011. (BRASIL, 2007a).

No ano de 2008 o ProJovem passou por reformulações, sendo regido desde então pela Lei $n^{\circ} 11.692$, de 10 de junho de 2008 (BRASIL, 2008c), portanto, suas mudanças contemplam tanto o pe- 
ríodo de 2004-2007, quanto 2008-2011, sendo integrado às ações do programa para emancipação da juventude no PPA 2012-2015.

O público-alvo na segunda etapa foi ampliado de jovens entre 18 e 24 anos para adolescentes a partir de 15 anos e jovens até 29 anos. A implementação do ProJovem se deu em caráter experimental e emergencial com o objetivo de executar ações integradas que propiciem aos jovens brasileiros elevação do grau de escolaridade, qualificação profissional e exercício da cidadania. A distinção entre os objetivos na implementação e na reformulação resume-se à educação. A primeira visava proporcionar aos jovens brasileiros elevação do grau de escolaridade, e a segunda, promover a sua reintegração ao processo educacional, isto é, atuar para que os jovens que estão fora da escola possam ser reintegrados ao sistema educacional. (BRASIL, 2005c; BRASIL, 2008b).

Além da Secretaria-Geral da Presidência da República, a execução do ProJovem passou a contar com a participação dos Ministérios da Educação (MEC), do Trabalho e Emprego (MTE) e do Desenvolvimento Social e Combate à Fome (MDS). A forma de execução foi facilitada, uma vez que a União ficou autorizada a transferir recursos do programa aos Estados, Distrito Federal e Municípios sem a necessidade de convênios. (BRASIL, 2008b).

O ProJovem foi implementado com durabilidade e previsão de avaliação ao término do período, o que representa uma conquista quanto ao ciclo das políticas públicas, tendo em vista a baixa previsibilidade legal de avaliação em grande parte dos programas. Não obstante, não há menção quanto ao tipo de avaliação pela qual deveria passar. Além do mais, não fica claro se as alterações apresentadas pela Lei $n^{\circ} 11.692 / 2008$ surgiram como resultado de alguma avaliação como estabelecida a priori ou se fazem parte de meras mudanças oriundas do contexto político.

Por outro lado, um estudo de caso divulgado pela Secretaria Nacional da Juventude (SNJ), em 2011, informou que diferentes avaliações foram realizadas no âmbito da Secretaria, inclusive com a produção de relatórios parciais sobre o programa. De acordo com o estudo, as lições aprendidas têm como foco a necessidade de melhora na escolaridade dos jovens, atenção especial quanto à sua vulnerabilidade social, bem como as dificuldades para superar os desafios que surgiram na própria gestão interna do programa. (BRASIL, 2011b). Entretanto, no PPA de 2012-2015, o programa foi reduzido 
POLÍTICAS PÚBLICAS PARA A JUVENTUDE NOS PLANOS PLURIANUAIS DE 2004-2007, 2008-2011, 2012-2015

para uma ação dentro do programa Autonomia e Emancipação da Juventude.

\section{CONCLUSÃO}

As políticas públicas para a juventude avançaram quanto aos direitos dos jovens. Os planos analisados demonstram que o percentual de recursos executados pela União para esse público tem sido crescente em relação à estimativa de arrecadação anual. Além da educação, outro tema latente à juventude relaciona-se aos programas de trabalho, emprego e renda, abordados de forma distinta em cada um dos planos. No PPA 2004-2007 consta como um mega-objetivo, sob o qual vários outros programas estão subordinados, mas com público-alvo distinto, e nem todos eles destinados especificamente para a juventude, não sendo, portanto, abordados neste trabalho. No PPA 2007-2011 não há referência ao tema como mega-objetivo ou objetivos do governo, mas o tema emprego e renda surge no Programa Crédito Orientado ao Desenvolvimento e Geração de Emprego e Renda, também sem menção direta à juventude como público-alvo. Já no PPA 2012-2015 o tema está inserido em um programa específico e destinado também à juventude.

Quanto ao ProJovem, sua reformulação modificou o público-alvo, a validade, a avaliação do programa, os órgãos responsáveis por sua execução, as modalidades, dentre outros aspectos. As mudanças em sua estrutura legal realizadas em 2008 foram novamente adaptadas no período 2012-2015. O que outrora era um programa específico tornou-se uma mera ação inserida no Programa de Autonomia e Emancipação da Juventude, cuja execução orçamentária foi de apenas $4,8 \%$ do valor orçado. Em outras palavras, apesar do tema Juventude estar presente com valores consideráveis em todos os planos plurianuais analisados, observa-se uma reduzida execução orçamentária, indicando que poucos recursos foram de fato direcionados aos programas destinados aos jovens.

Ante a realidade da crise econômica e política pela qual o País atravessa, espera-se que as partes envolvidas criem, de fato, objetivos e metas transparentes, com real empenho de recursos financeiros, para que os compromissos em prol da juventude, assumidos pelo Brasil na virada do último milênio, sejam verdadeiramente alcançados. 


\section{REFERÊNCIAS}

ABRAMO, L. Trabalho decente e juventude no Brasil: a construção de uma Agenda. In: INSTITUTO DE PESQUISA ECONÔMICA APLICADA. Mercado de trabalho: conjuntura e análise. Brasília, DF, ano 18, n. 55, ago. 2013. p. 39-44.

ARRETCHE, M. T. S. Políticas sociais no Brasil: descentralização em um Estado federativo. Revista Brasileira de Ciências Sociais, São Paulo, v. 14, n. 40, p. 111-141, jun. 1999.

BAUMAN, Z. A Cultura no Mundo Líquido Moderno. Rio de Janeiro: Zahar, 2013.

BILHIM, J. Políticas Públicas e Agenda Política. Revista de Ciências Sociais e Políticas, Lisboa, n. 2, p. 82-102, 2008.

BRASIL. Constituição (1988). Constituição da República Federativa do Brasil: texto constitucional promulgado em 5 de outubro de 1988. 33. ed. Brasília, DF: Câmara dos Deputados, 2010a.

. Ministério do Planejamento, Orçamento e Gestão. Secretaria de Planejamento e Investimentos Estratégicos. Plano Plurianual 20042007: projeto de lei. Brasília, DF, 2003. de revisão. Brasília, DF, 2006a.

Plano Plurianual 2004-2007: projeto de lei $\overline{\text { Brasília, }} \overline{\mathrm{DF}, 200} \overline{7 \mathrm{a} .}$

. Plano Plurianual 2008-2011: projeto de lei.

$\overline{\text { Brasília, }} \overline{\mathrm{DF}, 201} \overline{2 \mathrm{a} .}$

. Plano Plurianual 2012-2015: projeto de lei.

. Presidência da República. Lei no 10.873 , de 16 de janeiro de 2004. Estima a Receita e Fixa a Despesa da União para o Exercício de 2004. Diário Oficial da União, Brasília, DF, seção 1, 19 jan. 2004.

Lei no 11.096 , de 13 de janeiro de 2005. Institui o Programa Universidade para Todos - PROUNI, regula a atuação de entidades beneficentes de assistência social no ensino superior; altera a Lei $n^{\circ} 10.891$, de 9 de julho de 2004, e dá outras providências. Diário Oficial da União, Brasília, DF, 14 jan. 2005a. Seção 1.

Lei $\mathrm{n}^{\circ} 11.100$, de 25 de janeiro de 2005. Estima a receita e fixa a despesa da União para o exercício financeiro de 2005 Diário Oficial da União, Brasília, DF, seção 1, 26 jan. 2005 b.

Lei $\mathrm{n}^{\mathrm{o}} 11.129$, de 30 de junho de 2005. Institui

o Programa Nacional de Inclusão de Jovens - ProJovem; cria o 
POLÍTICAS PÚBLICAS PARA A JUVENTUDE NOS PLANOS PLURIANUAIS DE 2004-2007, 2008-2011, 2012-2015

Conselho Nacional da Juventude - CNJ e a Secretaria Nacional de Juventude; altera as Leis $n^{\circ}$ s 10.683, de 28 de maio de 2003, e 10.429, de 24 de abril de 2002; e dá outras providências. Diário Oficial da União, Brasília, DF, seção 1, 1 jul. 2005c.

Lei $\mathrm{n}^{\circ} 11.306$, de 16 de maio de 2006. Estima a

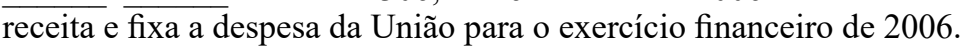
Diário Oficial da União, Brasília, DF, seção 1, 17 maio 2006b.

Lei $\mathrm{n}^{\mathrm{o}} 11.451$, de 7 de fevereiro de 2007. Estima a receita e fixa a despesa da União para o exercício financeiro de 2007. Diário Oficial da União, Brasília, DF, seção 1, 8 fev. 2007b.

Lei $\mathrm{n}^{\circ} 11.647$, de 24 de março de 2008. Estima a receita e fixa a despesa da União para o exercício financeiro de 2008. Diário Oficial da União, Brasília, DF, seção 1, edição extra, 24 mar. 2008a.

. Lei $\mathrm{n}^{\circ} 11.653$, de 7 de abril de 2008. Dispõe sobre o Plano Plurianual para o período 2008/2011. Diário Oficial da União, Brasília, DF, 8 abr. 2008b. Seção 1.

Lei $\mathrm{n}^{\circ} 11.692$, de 10 de junho de 2008. Dispõe sobre o Programa Nacional de Inclusão de Jovens - Projovem, instituído pela Lei $n^{\circ} 11.129$, de 30 de junho de 2005; altera a Lei ${ }^{\circ} 10.836$, de 9 de janeiro de 2004; revoga dispositivos das Leis $n^{\circ} \mathrm{s} 9.608$, de 18 de fevereiro de 1998, 10.748, de 22 de outubro de 2003, 10.940, de 27 de agosto de 2004, 11.129, de 30 de junho de 2005, e 11.180, de 23 de setembro de 2005; e dá outras providências. Diário Oficial da União, Brasília, DF, seção 1, 11 jun. 2008c.

Lei $n^{\circ} 11.897$, de 30 de dezembro de 2008. Estima a receita e fixa a despesa da União para o exercício financeiro de 2009. Diário Oficial da União, Brasília, DF, seção 1, 31 jan. 2008d.

Lei $\mathrm{n}^{\circ} 12.214$, de 26 de janeiro de 2010. Estima a receita e fixa a despesa da União para o exercício financeiro de 2010. Diário Oficial da União, Brasília, DF, seção 1, 27 jan. 2010 b.

Lei $\mathrm{n}^{\circ}$ 12.381, de 9 de fevereiro de 2011. Estima a receita e fixa a despesa da União para o exercício financeiro de 2011. Diário Oficial da União, Brasília, DF, seção 1, 10 fev. 2011a.

Lei $\mathrm{n}^{\circ} 12.593$, de 18 de janeiro de 2012. Institui o Plano Plurianual da União para o período de 2012 a 2015. Diário Oficial da União, Brasília, DF, seção 1, 19 jan. 2012 b. 
BRASIL. Presidência da República. Lei no 12.595 , de 19 de janeiro de 2012. Estima a receita e fixa a despesa da União para o exercício financeiro de 2012. Diário Oficial da União, Brasília, DF, 20 jan. 2012c. Seção 1.

Lei $\mathrm{n}^{\circ} 12.798$, de 4 de abril de 2013. Estima a receita e fixa a despesa da União para o exercício financeiro de 2013. Diário Oficial da União, Brasília, DF, seção 1, 5 abr. 2013a.

. Lei $\mathrm{n}^{\mathrm{o}} 12.852$, de 5 de agosto de 2013. Institui o Estatuto da Juventude e dispõe sobre os direitos dos jovens, os princípios e diretrizes das políticas públicas de juventude e o Sistema Nacional de Juventude - SINAJUVE. Diário Oficial da União, Brasília, DF, seção 1, 6 ago. 2013b.

. Lei $\mathrm{n}^{\mathrm{o}} 12.952$, de 20 de janeiro de 2014. Estima a

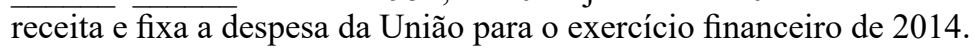
Diário Oficial da União, Brasília, DF, seção 1, supl., 21 jan. 2014.

. Lei $\mathrm{n}^{\mathrm{o}} 13.115$, de 20 de abril de 2015. Estima a receita e fixa a despesa da União para o exercício financeiro de 2015. Diário Oficial da União, Brasília, DF, seção 1, 22 abr. 2015.

. Secretaria Nacional de Juventude. Programa Nacional de Inclusão de Jovens - ProJovem: estudo de caso apresentado durante evento paralelo do Encontro de Alto Nível das Nações Unidas sobre Juventude, 25-26 de julho de 2011. New York, jul. 2011b. Disponível em $<$ http://www.unfpa.org.br/Arquivos/pro_jovem.pdf $>$. Acesso em: 30 dez. 2016.

. Senado Federal. Sistema Integrado de Administração Financeira. Séries Históricas. Execução orçamentária por programação. Base de Dados SIAFI. Brasília, DF, 2016. Disponível em: $<$ https://www12.senado.leg.br/orcamento/loa $>$. Acesso em: 25 dez. 2016.

CARVAlHO, F. X. de; NOMA, A. K. Políticas Públicas para a Juventude na Perspectiva Neoliberal: a centralidade da Educação. Roteiro, Joaçaba, v. 36, n. 1, p. 167-186, jan./jun. 2011.

DAYRELL, J. O jovem como sujeito social. Revista Brasileira de Educação, Rio de Janeiro, n. 24, p. 40-52, set./dez. 2003.

DENHARDT, R. B. Teorias da Administração Pública. 6. ed.São Paulo: Cengage Learning, 2012. 
POLÍTICAS PÚBLICAS PARA A JUVENTUDE NOS PLANOS PLURIANUAIS DE 2004-2007, 2008-2011, 2012-2015

DESSEN, M. A.; POLONIA, A. da C. A família e a escola como contextos de desenvolvimento humano. Paidéia, Ribeirão Preto, v. 17, n. 36, p. 21-32, jan./abr. 2007.

FEIXA, C.; LECCARDI, C. O conceito de geração nas teorias sobre juventude. Sociedade e Estado, Brasília, DF, v. 25, n. 2, p. 185-204, maio/ago. 2010.

HOOD, C. A Public Management for all Seasons? Public Administration, [S. 1.], v. 69, n. 1, p. 3-19, mar. 1991.

JACCOUD, L. (Org.). Questão social e políticas sociais no Brasil contemporâneo. Brasília, DF: IPEA, 2005.

NUNES, A.; OLIVEIRA, R. B.; BEÚ, R. B. O Orçamento-Programa no Contexto da Gestão Pública. Revista Eletrônica em Gestão, Educação e Tecnologia Ambiental, Santa Maria, v. 19, n. 3, p. 424432, set./dez. 2015.

ORGANIZAÇÃO DAS NAÇÕES UNIDAS. Declaração do Milênio. Nova Iorque, 2000. Disponível me: $<$ www.undp.org/hdr2001>. Acesso em: 20 dez. 2016.

ORGANIZAÇÃO MUNDIAL DE SAÚDE. La salud del adolescente y el joven em las Américas. Washington, D.C., 1985. Disponível em: $<$ http://pesquisa.bvsalud.org/eportuguese/resources/resources/ resources/lil-36873>. Acesso em: 10 ago 2017.

PEDROSO, M. C.; SALLES, L. M. F. Políticas públicas para a juventude. In: CONGRESSO NACIONAL DE FORMAÇÃO DE PROFESSORES, 2., CONGRESSO ESTADUAL PAULISTA SOBRE FORMAÇÃO DE EDUCADORES, 12., São Paulo, 2014. Anais... São Paulo: UNESP, 2014. p. 4325-4334.

SCHMITZ, G. de O. O Brasil e a Parceria Global no Contexto de uma agenda Pós-2015 para o Desenvolvimento: tendências e incertezas. In: INSTITUTO DE PESQUISA ECONÔMICA APLICADA Brasil em Desenvolvimento 2014: estado, planejamento e políticas públicas. Brasília, DF, 2014. v. 2, p. 445- 464.

SILVA, C. R.; LOPES, R. E. Adolescência e juventude: entre conceitos e políticas públicas. Cadernos de Terapia Ocupacional da UFSCar, São Carlos, SP, v. 17, n. 2, p. 87-106, jul./dez. 2009.

R. S. da; SILVA, V. R. da. Política Nacional de Juventude: trajetória e desafios. Caderno CRH, Salvador, v. 24, n. 63, p. 663678, set./dez. 2011. 
SOUZA, C. Políticas Públicas: uma revisão de literatura. Sociologias, Porto Alegre, v. 8, n. 16, p. 20-45, jul./dez. 2006.

SPOSITO, M. P.; CARRANO, P. C. R. Juventude e políticas públicas no Brasil. Revista Brasileira de Educação, Rio de Janeiro, n. 24, p. 16-39, set./dez. 2003. Disponível em: $<$ http://www.scielo.br/pdf/\%0D/ rbedu/n24/n24a03.pdf > . Acesso em: 10 ago 2017.

TREVISAN, A. P.; VAN BELLEN, H. M. Avaliação de políticas públicas: uma revisão teórica de um campo em construção. Revista de Administração Pública, Rio de Janeiro, v. 42, n. 3, p. 529-550, maio/ jun. 2008.

VALADARES, A. A.; GALIZA, M. Previdência Rural: contextualizando o debate em torno do financiamento e das regras de acesso. Brasília, DF: IPEA, maio 2016. (Nota Técnica, n. 25).

ZAPPE, J.; DELL'AGLIO, D. D. Adolescência em diferentes contextos de desenvolvimento: risco e proteção em uma perspectiva longitudinal. Psico, Porto Alegre, v. 47, n. 2, p. 99-110, 2016.

\section{Notas}

1 Os autores reconhecem o uso do conceito juventudes por vários autores, quando se trata de realidades sociais tão distintas, mas neste texto utilizaremos o termo Juventude para dialogar com a nomenclatura utilizada nos marcos legais e orçamentários quando se referem a este público.

2 Cabe ainda distinguir a existência e relevância de programas diretamente relacionados à juventude e que não constam como programas específicos nos Planos, uma vez que são subordinados diretamente a Ministérios ou Secretarias de Governo, como é o caso do Programa Universidade para Todos (PROUNI), subordinado ao Ministério da Educação (MEC) (BRASIL, 2005a), e demais programas ligados à Secretaria Nacional de Juventude (SNJ). No intuito de ater-se diretamente nas ações que explicitam o termo juventude nos PPA e à sua execução, é que este trabalho delimita seu escopo de análise. 